Genetic Epidemiology 15:215-223 (1998)

\title{
Validity of Family History for the Diagnosis of Dementia Among Siblings of Patients With Late-onset Alzheimer's Disease
}

\author{
G. Devi, ${ }^{1,3 *}$ K. Marder, ${ }^{1,3}$ P.W. Schofield, ${ }^{1,3}$ M.X. Tang, ${ }^{1,5}$ Y. Stern,,${ }^{1,2}$ and \\ R. Mayeux ${ }^{1,2,3,4}$
}

${ }^{1}$ Gertrude H. Sergievsky Center, Division of Epidemiology, Columbia University School of Public Health, New York, New York

${ }^{2}$ Taub Center for Alzheimer's Disease, New York, New York

${ }^{3}$ Department of Neurology, College of Physicians and Surgeons, Columbia University, New York, New York

${ }^{4}$ Department of Psychiatry, College of Physicians and Surgeons, Columbia University, New York, New York

${ }^{5}$ Division of Biostatistics, Columbia University School of Public Health, New

York, New York

\begin{abstract}
We examined 180 siblings of 127 probands with probable or possible Alzheimer's dementia (AD) in a family study of AD. The overall sensitivity of a simple family history questionnaire was $64 \%$ and the specificity was $84 \%$. Sensitivity improved 90-100\% with minimal decline in specificity when we considered clinic-based vs. population survey patients. Higher education among informants and the availability of a spouse or a sibling as informant significantly increased sensitivity. Awareness of such factors may improve the yield of the family history in AD using a simple questionnaire. Genet. Epidemiol. 15:215223, 1998. (c) 1998 Wiley-Liss, Inc.
\end{abstract}

Key words: Alzheimer's disease; family history; validity

\section{INTRODUCTION}

We need accurate information about the presence or absence of dementia in relatives of probands with Alzheimer's dementia (AD) to study its genetic basis. The

\footnotetext{
*Correspondence to: Gayatri Devi, M.D., G.H. Sergievsky Center, 630 W. 168th Street, New York, NY 10032. E mail: devigay@ sergievsky.cpmc.columbia.edu
}

Received 10 January 1997; Revised 21 July 1997; Accepted 23 July 1997

(C) 1998 Wiley-Liss, Inc. 
family history method uses information obtained from the probands, relatives, spouses, or caregivers to identify dementia in relatives. The validation of this method in AD by direct examination of relatives at risk (the family study method) has not yet been done.

Although the family history method is efficient at screening large numbers of relatives, it underestimates true disease prevalence [Andreasen et al., 1977]. This is valid for illnesses as diverse as psychiatric disorders, migraines, or isolated seizure episodes [Mendlewicz et al., 1975; Andreasen et al., 1986; Ottman et al., 1993a,b]. However, direct examination of relatives at risk poses unique problems in $\mathrm{AD}$ [Silverman et al., 1986, 1989]. Due to the late age of onset of AD, parents of probands may not be alive and children of probands may be too young to develop AD. Death certificates are not reliable to establish a diagnosis and also may be unavailable due to the time elapsed since the death of a relative [Silverman et al., 1989].

We examined available siblings of probands with $\mathrm{AD}$ in order to determine the validity of a family history for a diagnosis of $\mathrm{AD}$ or $\mathrm{AD}$-like dementias. We attempted to answer the following questions: (1) how sensitive and specific is the family history for a diagnosis of $\mathrm{AD}$, and (2) What informant and sibling characteristics affect the sensitivity of the family history for a diagnosis of dementia? We analyzed the response to a screening question for $\mathrm{AD}$ in an extensive family history questionnaire administered to informants of probands for all first-degree relatives of the proband. However, only the siblings were examined as part of a study of genetics in AD. Because only a single screening question was analyzed, such a family history may have applicability in both research and practice settings.

\section{METHODS}

Probands were patients identified from two different sources: referrals from a memory disorders clinic in a tertiary care center and from a random sample of Medicare recipients in a New York City community. All probands were examined by a neurologist who completed a structured medical and neurological examination. Each patient had received a neuropsychological battery by a trained tester. Clinical data were reviewed at a consensus conference of neurologists and neuropsychologists using the NINCDS-ADRDA criteria [McKhann et al., 1984] to establish diagnoses. These methods and their development have been previously described [Gurland et al., 1995].

All probands and their families provided informed consent. Family members of AD probands were given a structured family history for each of the probands' firstdegree relatives by a trained interviewer either via telephone or in person. There were two screen questions for $\mathrm{AD}$. We analyzed the response to the following question: Did the family member have memory loss, senility, dementia, Alzheimer's disease, hardening of the arteries, or other mental changes? The second question-Was the person unable to care for him/herself? - was endorsed in the absence of the first on one occasion only and thus only the first question was evaluated. An affirmative answer to question 1 was taken as a positive family history of $\mathrm{AD}$. If either of the two was answered in the affirmative, a follow-up battery of 10 questions regarding $\mathrm{AD}$ was asked. However, we found that the analysis of the first question was the most sensitive of all the questions for a diagnosis of dementia. When follow-up questions were answered in the affirmative, the specificity improved, but the sensitivity diminished significantly. 
Demographic information about the informant was also obtained. We then examined all available siblings using the same procedure as described for probands. Most resided in the area and vicinity, some in surrounding states and foreign countries. We attempted to see all available affected and unaffected relatives.

Demographic variables describing the informant and the siblings, including age, education, gender, were analyzed using the Student's t-test for continuous variables of Chi-square analysis for categorical variables (SPSS statistical package).

Where there were two or more informants for an individual proband, the primary caregiver was designated as the primary informant and his or her demographic features were analyzed.

\section{RESULTS}

There were 127 probands with a diagnosis of probable or possible AD. Of these, information on sibships for five probands were missing. For the remaining 122 probands, information on sibships was analyzed. There were 612 siblings with six members in the average sibship (mean and median, 6; range, 2-15). Of these 257 $(42 \%)$ were dead, $345(56 \%)$ were alive, and the status of the remaining 10 was unknown. Of the 612 siblings, $326(53 \%)$ were men and $286(47 \%)$ were women. There were 324 siblings who were alive and who did not have a missing variable for the AD family history question. Of 64 siblings for whom a positive family history of AD was reported by an informant, 53, or $83 \%$, were seen. Of 260 siblings with a negative screen for family history, 116 , or $45 \%$, were seen.

Those seen were marginally less educated $(8.2 \pm 5.9 \mathrm{yr})$ than those siblings who were not seen $(8.3 \pm 5.6 \mathrm{yr}, P<0.02)$. There was no difference in sibship size among those seen and not seen. There was no difference in ages between siblings seen and not seen. More women $(58 \%)$ than men $(39 \%)$ were seen $(P<0.0000)$, although $71 \%$ of the males, but only $55 \%$ of the women were reported to have a positive family history $(P<0.0001)$. However, of those siblings who were reported to have memory problems, $12 / 16(75 \%)$ men and $41 / 48(85 \%)$ of women were seen $(P<$ $0.3)$. Of those who were not reported to have memory complaints, 52/134 (39\%) of the men and 64/129 (51\%) of the women $(P<0.05)$ were seen.

Demographic characteristics of siblings seen are listed in Table I. Among the 127 probands seen, men had more education than women (men, $12.8 \mathrm{yr}$ (sd 6.2); women, $6.9 \mathrm{yr}(\mathrm{sd} \pm 5.6) ; P<0.0001)$. For the purposes of analysis, Hispanic and African-American subjects were grouped together as the results were nearly identical for these two groups. Caucasian siblings were better educated than the other two groups (Caucasians $14.2 \mathrm{yr}(\mathrm{sd} \pm 4.2)$; Hispanics and African Americans $5.2 \mathrm{yr}$ ( $\mathrm{sd} \pm$ 4.8); $P<0.0001)$.

Of the 185 siblings seen, five had either unknown or missing information for the screening question on $\mathrm{AD}$. All five were non-Caucasian ( 2 men and 3 women) and both men had probable AD. These five were not included in our analysis, leaving us with 180 siblings whose data we analyzed.

The overall sensitivity of the family history of $\mathrm{AD}$ for a diagnosis of $\mathrm{AD}$ was $63 \%$ and the overall specificity was $84 \%$ (see Table II). The overall prevalence of dementia among siblings of probands with AD was $31 \%$ (56/180). The prevalence of $\mathrm{AD}$ in particular was $30 \%$ or $41 \%$, after including very mild $\mathrm{AD}$ (clinical dementia rating of 0.5) [Morris et al., 1991]. 
TABLE I. Demographics

\begin{tabular}{lccc}
\hline Variable & Probands & Siblings & Informants \\
\hline Number & 127 & 180 & 180 \\
Age $(\mathrm{yr})$ & $74 \pm 9(45-92)$ & $75 \pm 9(46-94)$ & $61 \pm 17(25-89)$ \\
Education (yr) & $9 \pm 6(0-20)$ & $8 \pm 6(0-20)$ & $11 \pm 6(0-21)$ \\
Men & $41(32 \%)$ & $67(37 \%)$ & $35(19 \%)$ \\
Women & $86(68 \%)$ & $113(63 \%)$ & $145(81 \%)$ \\
African American & $8(6 \%)$ & $10(5 \%)$ & $8(4 \%)$ \\
Caucasian & $57(45 \%)$ & $73(41 \%)$ & $76(42 \%)$ \\
Hispanic & $62(49 \%)$ & $97(54 \%)$ & $96(54 \%)$ \\
Normal & 0 & $124(69 \%)$ & $146(81 \%)$ \\
Probable AD & $103(81 \%)$ & $42(23 \%)$ & $34(19 \%)$ \\
Possible AD & $24(19 \%)$ & $11(6 \%)$ & 1 \\
Other dementia & 0 & $3(2 \%)$ & 1 \\
Community & $51(40 \%)$ & $74(41 \%)$ & $74(41 \%)$ \\
Clinic & $76(60 \%)$ & $106(59 \%)$ & $106(59 \%)$ \\
\hline
\end{tabular}

Depending on the subcategory (e.g., clinic vs. community survey; male vs. female siblings), sensitivity of a family history of dementia varied from $21 \%$ to $100 \%$, whereas the specificity remained relatively stable at $68 \%$ to $100 \%$. These subgroups are listed in Table II, along with the respective sensitivities and specificities. The population base was an important source of variability of the sensitivity of family history for a diagnosis of dementia. For siblings of probands from the clinic, who had sought our medical care with complaints of memory problems, the sensitivity of the family history was $91 \%$ and specificity was $80 \%$. For siblings of probands who were found to have dementia in a community survey of the elderly, the sensitivity drops to $42 \%$ with a specificity of $93 \%$.

Informants for the clinic population were more educated $(14.2 \pm 3.5 \mathrm{yr})$ than community informants $(5.3 \pm 4.9 \mathrm{yr}, P<0.0000)$. More of the clinic informants were primary caregivers $(83 / 106 ; 78 \%)$ than in the community $(48 / 74 ; 64 \% ; P<0.05)$. There were more women informants in the community $(66 / 74 ; 89 \%)$ than in the clinic $(79 / 106 ; 75 \% ; P<0.01)$. Probands from the clinic were more likely to have a spouse or sibling as an informant (see Table III).

The informants were children $(69 / 180 ; 38 \%)$, spouses of probands (sisters or brothers in law of siblings) (41/180; 23\%), probands (demented siblings of siblings) $(31 / 180 ; 17 \%)$, siblings $(24 / 180 ; 13 \%)$, or others $(15 / 180 ; 8 \%)$. Where probands were the informants, their clinical dementia severity was very mild $(11 / 31 ; 35 \%)$, mild $(16 / 31 ; 52 \%)$, or moderate $(4 / 31 ; 13 \%)$.

When the population was stratified by those informants with and without at last a year of high school education, the family history was more sensitive among more educated informants (sensitivity $85 \%, 23 / 27$; specificity $82 \%, 72 / 88$ ) than less educated informants (sensitivity 33\%; 5/15; specificity $87 \%, 20 / 23 ; P<0.04$ ), and the difference in sensitivities between community and clinic populations was reduced. For instance, among those with a high school education, the sensitivities were $90 \%$ and $70 \%$ for clinic and community siblings, respectively.

The gender of the informant did not significantly alter the sensitivity of the family history. However, male siblings were less likely to be reported as demented when compared to female siblings especially in the community (see Table II), and 
TABLE II. Sensitivity and Specificity for a Diagnosis of Dementia for Varying Informant and Sibling Characteristics

\begin{tabular}{|c|c|c|c|c|c|c|c|c|c|}
\hline & \multicolumn{3}{|c|}{ Clinic \& community populations } & \multicolumn{3}{|c|}{ Clinic population } & \multicolumn{3}{|c|}{ Community population } \\
\hline & $\mathrm{N}$ & Sensitivity; N & Specificity; N & $\mathrm{N}$ & Sensitivity; N & Specificity; N & $\mathrm{N}$ & Sensitivity; N & Specificity; N \\
\hline Overall & 180 & $63 \% ; 35 / 56$ & $84 \% ; 104 / 124 P<0.000$ & 106 & $91 \% ; 21 / 23$ & $80 \% ; 66 / 83 P<0.000$ & 74 & $42 \% ; 14 / 33$ & $93 \% ; 38 / 41 P<0.000$ \\
\hline \multicolumn{10}{|l|}{ Informants } \\
\hline Men & 35 & $90 \% ; 9 / 10$ & $80 \% ; 20 / 25 P<0.000$ & 27 & $100 \% ; 5 / 5$ & $82 \% ; 18 / 22 P<0.000$ & 8 & $80 \% ; 4 / 5$ & $67 \% ; 2 / 3 P<0.2$ \\
\hline Women & 145 & $57 \% ; 26 / 46$ & $85 \% ; 84 / 99 P<0.000$ & 79 & $89 \% ; 16 / 18$ & $79 \% ; 48 / 61 P<0.000$ & 66 & $36 \% ; 10 / 28$ & $95 \% ; 36 / 38 P<0.002$ \\
\hline White & 76 & $92 \% ; 12 / 13$ & $81 \% ; 51 / 63 P<0.000$ & 75 & $92 \% ; 11 / 12$ & $81 \% ; 51 / 63 P<0.000$ & 1 & - & - \\
\hline Non-white & 104 & $54 \% ; 23 / 43$ & $87 \% ; 53 / 61 P<0.000$ & 31 & $91 \% ; 10 / 11$ & $75 \% ; 15 / 20 P<0.000$ & 73 & $41 \% ; 31 / 32$ & $93 \% ; 38 / 41 P<0.000$ \\
\hline$>8 \mathrm{yr}$ education & 115 & $85 \% ; 23 / 27$ & $82 \% ; 72 / 188 P<0.000$ & 94 & $90 \% ; 18 / 20$ & $78 \% ; 58 / 74 P<0.000$ & 21 & $71 \% ; 5 / 7$ & $100 \% ; 14 / 14 P<0.000$ \\
\hline$\leq 8 \mathrm{yr}$ education & 38 & $33 \% ; 5 / 15$ & $87 \% ; 20 / 23 P<0.000$ & 6 & $100 \% ; 1 / 1$ & $100 \% ; 5 / 5 P<0.01$ & 32 & $29 \% ; 4 / 14$ & $83 \% ; 15 / 18 P<0.45$ \\
\hline In person & 31 & $89 \% ; 8 / 9$ & $68 \% ; 5 / 22 P<0.003$ & 19 & $100 \% ; 5 / 5$ & $50 \% ; 7 / 14 P<0.05$ & 12 & $75 \% ; 3 / 4$ & $100 \% ; 8 / 8 P<0.005$ \\
\hline Telephone & 149 & $57 \% ; 27 / 47$ & $87 \% ; 89 / 102 P<0.000$ & 87 & $89 \% ; 16 / 18$ & $86 \% ; 59 / 69 P<0.000$ & 62 & $38 \% ; 11 / 29$ & $91 \% ; 30 / 33 P<0.007$ \\
\hline Caregiver & 131 & $68 \% ; 25 / 37$ & $82 \% ; 77 / 94 P<0.000$ & 83 & $90 \% ; 17 / 19$ & 78\%; 50/64 $P<0.000$ & 48 & $44 \% ; 8 / 18$ & $90 \% ; 27 / 30 P<0.006$ \\
\hline Not caregiver & 49 & $53 \% ; 10 / 19$ & $90 \% ; 27 / 30 P<0.001$ & 23 & $100 \% ; 4 / 4$ & $84 \% ; 16 / 19 P<0.000$ & 26 & $40 \% ; 2 / 5$ & $100 \% ; 11 / 11 P<0.02$ \\
\hline$\geq 2$ informants & 52 & $71 \% ; 5 / 7$ & $91 \% ; 41 / 48 P<0.000$ & 45 & $83 \% ; 5 / 6$ & $90 \% ; 35 / 39 P<0.000$ & 7 & - & - \\
\hline 1 informant & 128 & $61 \% ; 30 / 49$ & $80 \% ; 63 / 79 P<0.000$ & 61 & $94 \% ; 16 / 17$ & $70 \% ; 31 / 44 P<0.000$ & 67 & $44 \% ; 14 / 32$ & $91 \% ; 32 / 35 P<0.001$ \\
\hline \multicolumn{10}{|l|}{ Siblings } \\
\hline Men & 67 & $21 \% ; 3 / 14$ & $81 \% ; 43 / 53 \quad P<0.8$ & 42 & $100 \% ; 2 / 2$ & $80 \% ; 32 / 40 \quad P<0.01$ & 25 & $8 \% ; 1 / 12$ & $85 \% ; 11 / 13 P<0.6$ \\
\hline Women & 113 & $76 \% ; 32 / 42$ & $86 \% ; 61 / 71 P<0.000$ & 64 & $91 \% ; 19 / 21$ & $79 \% ; 34 / 43 P<0.000$ & 49 & $62 \% ; 13 / 21$ & $96 \% ; 27 / 28 P<0.000$ \\
\hline$>8 \mathrm{yr}$ education & 79 & $52 \% ; 17 / 33$ & $85 \% ; 39 / 46 P<0.000$ & 81 & $100 \% ; 12 / 12$ & $81 \% ; 56 / 69 P<0.000$ & 19 & $50 \% ; 5 / 10$ & $100 \% ; 9 / 9 P<0.01$ \\
\hline$\leq 8 \mathrm{yr}$ education & 100 & $77 \% ; 17 / 22$ & $83 \% ; 65 / 78 P<0.000$ & 24 & $80 \% ; 8 / 10$ & $71 \% ; 10 / 14 P<0.02$ & 55 & $39 \% ; 9 / 23$ & $91 \% ; 29 / 32 \quad P<0.01$ \\
\hline White & 73 & $100 \% ; 11 / 11$ & $81 \% ; 50 / 62 P<0.000$ & 72 & $100 \% ; 10 / 10$ & $81 \% ; 50 / 62 P<0.000$ & 1 & - & - \\
\hline Nonwhite & 107 & $53 \% ; 24 / 45$ & $87 \% ; 54 / 62 P<0.000$ & 34 & $85 \% ; 11 / 13$ & $76 \% ; 16 / 21 P<0.000$ & 73 & $40 \% ; 13 / 32$ & $93 \% ; 38 / 41 P<0.000$ \\
\hline
\end{tabular}


TABLE III. Famiily Members as Informants*

\begin{tabular}{|c|c|c|c|c|c|}
\hline Variable & $\begin{array}{c}\text { Spouse } \\
\mathrm{N}=41(23 \%)\end{array}$ & $\begin{array}{c}\text { Sibling } \\
\mathrm{N}=24(13 \%)\end{array}$ & $\begin{array}{l}\text { Child } \\
\mathrm{N}=69(38 \%)\end{array}$ & $\begin{array}{c}\text { Proband } \\
\mathrm{N}=31(17 \%)\end{array}$ & $\begin{array}{c}\text { Other } \\
\mathrm{N}=15(8 \%)\end{array}$ \\
\hline Sensitivity \% (N) & $88 \%(7 / 8)$ & $100 \%(3 / 3)$ & $61 \%(14 / 23)$ & $39 \%(5 / 13)$ & $67 \%(6 / 9)$ \\
\hline Specificity \% (N) & $\begin{array}{c}82 \%(27 / 33) \\
P<0.000\end{array}$ & $\begin{array}{c}81 \%(17 / 21) \\
P<0.004\end{array}$ & $\begin{array}{c}80 \%(37 / 46) \\
P<0.001\end{array}$ & $\begin{array}{c}100 \%(18 / 18) \\
P<0.004\end{array}$ & $\begin{array}{c}83 \%(5 / 6) \\
P<0.06\end{array}$ \\
\hline Age (yr) & Missing & $74 \pm 10(57-87)$ & $46 \pm 10(25-65)$ & $76 \pm 7(61-89)$ & $65 \pm 8(58-73)$ \\
\hline Education (yr) & $14 \pm 4(3-20)$ & $12 \pm 4(5-18)$ & $12 \pm 5(0-21)$ & $3 \pm 5(0-16)$ & $15 \pm 4(12-20)$ \\
\hline Men & $34 \%(14)$ & $29 \%(7)$ & $10 \%(7)$ & $10 \%(3)$ & $27 \%$ \\
\hline Women & $66 \%(27)$ & $71 \%(17)$ & $90 \%(62)$ & $90 \%(28)$ & $73 \%(11)$ \\
\hline Primary caregiver & $98 \%(40)$ & $37 \%(9)$ & $93 \%(64)$ & $23 \%(7)$ & $73 \%(11)$ \\
\hline Not primary caregiver & $2 \%(1)$ & $63 \%(15)$ & $7 \%(5)$ & $77 \%(24)$ & $27 \%(4)$ \\
\hline Telephone & $93 \%(38)$ & $54 \%(13)$ & $84 \%(58)$ & $94 \%(29)$ & $73 \%(11)$ \\
\hline Person & $7 \%(3)$ & $46 \%(11)$ & $16 \%(11)$ & $6 \%(2)$ & $27 \%(4)$ \\
\hline Clinic & $93 \%(38)$ & $88 \%(21)$ & $55 \%(38)$ & $10 \%(3)$ & $40 \%(6)$ \\
\hline Community & $7 \%(3)$ & $13 \%(3)$ & $45 \%(31)$ & $90 \%(28)$ & $60 \%(9)$ \\
\hline
\end{tabular}

*Proband's spouse would be sibling's in-law; proband's child would be sibling's niece/nephew. 
this difference was significant $(P<0.002)$. There was, however, no difference in education between male $(8.9 \pm 6.3 \mathrm{yr})$ and female $(7.8 \pm 5.2 \mathrm{yr}, P<0.2)$ siblings.

\section{DISCUSSION}

In this mixture of cases from a tertiary medical center and a random sample of the elderly, the overall sensitivity of the family history questionnaire for AD was $64 \%$ and the specificity was $83 \%$.

A number of factors improve the sensitivity of the family history, but the primary criterion appears to be education. This appears to be the reason for the high sensitivities of $90 \%$ or more among the siblings and informants of the clinic probands who on the average had at least 5 more years of education than their community peers. Furthermore, gender appears to play a role in sensitivity. Only $21 \%$ of male siblings were correctly reported to be demented as compared to $76 \%$ of the female siblings with minimal differences in specificity and education. The underreporting appears to arise primarily from the community population in which only 1 of 13 male siblings with dementia was reported to be demented as compared to 13 of 21 female siblings. The male siblings in the community were, however, only slightly better educated (men, $5.8 \pm 4.6 \mathrm{yr}$; women, $3.3 \pm 4 \mathrm{yr} ; P<0.01$ ). Spouses and siblings of the proband appear to provide more valid family histories than children of the probands themselves. Not surprisingly personal interviews were more sensitive than telephone interviews.

The sensitivity of family histories for various psychiatric disorders such as depression, alcoholism, and schizophrenia range from $31 \%$ to $50 \%$, with specificities from $89 \%$ to $100 \%$ [Andreasen et al., 1986]. For neurologic illnesses such as migraine and epilepsy, the sensitivity has ranged from $54 \%$ to $74 \%$ and the specificity up to $86 \%$ [Ottman et al., 1993a,b]. Our values of $63 \%$ sensitivity and $84 \%$ specificity are comparable.

Although a few studies have examined the validity of the family history by retrospectively questioning relatives of dead patients or asking enrolled patients to supply informants, ours is the first large study to validate the family history method by the family study method.

Although Heun and Maier [1995] evaluated 228 relatives of 49 patients with $\mathrm{AD}$ and 40 controls, they found a sensitivity of the family history of only $25 \%$. The specificity was not stated, nor were methodological issues such as how diagnosis of $\mathrm{AD}$ was made and by whom as well as the characteristics of the informants. Hence, the reason for the especially low sensitivity could not be discerned.

Kawas et al. [1994] found a sensitivity of $100 \%$ and a specificity of $90 \%$ in a group of subjects enrolled in longitudinal study of aging. Probands were diagnosed as demented or normal using NINCDS-ADRDA criteria. They were then asked to name an appropriate informant who was then administered a questionnaire via telephone by a tester. These subjects were from a volunteer cohort and of higher socioeconomic and educational levels (most had had at least 14 years of education) than in the present study. In our clinic population, which had somewhat similar demographics $(10.9 \pm 5.1 \mathrm{yr}$ of education), the sensitivity was $91 \%$ and specificity $80 \%$.

The lower rates may reflect the very select nature of the Kawas et al. [1994] study group as well as the subject's ability to choose a particular person as the informant. 
When we limited our clinic population to Caucasian patients with $>8$ years of education, our sensitivity rose to $100 \%$ (9/9) and the specificity was stable at $80 \%(49 / 61)$. The average education of the community individuals was $4.4 \pm 4.0$ years.

Validation of family history by retrospectively questioning the relatives of autopsied patients with AD gives similar high values for sensitivity and specificity. Kukull et al. [1989] questioned relatives of 36 patients with confirmed AD or other dementias. The diagnosis of $\mathrm{AD}$ as derived from the questionnaire had a sensitivity of $93 \%$ and a specificity of $43 \%$ for autopsy confirmed AD. However, all these patients were enrolled in longitudinal dementia studies, and their relatives were involved study participants. As such, these informants would be expected to be aware of memory loss in their relatives, giving the high sensitivity and low specificity values observed.

Li et al. [1997] validated the family history by interviewing family members of 77 elderly nursing home subjects with dementia, all of whom had been autopsied. They found the sensitivity of the family history method to be $84 \%$ and specificity to be $67 \%$. Information about the informants was not given, although the informants were presumably involved in consenting to have their relatives autopsied. As such they would be assumed to have some idea that the relative had had a neurodegenerative process.

Our study evaluated the validity of the family history method for a diagnosis of dementia and attempted to identify factors that may improve the sensitivity of the family history method. Other groups have evaluated other aspects of the family history method for a diagnosis of AD. Silverman et al. [1986, 1989] established interinformant and interrater reliability using a family history questionnaire for the diagnosis of AD. The good interinformant reliability was confirmed in another study by Mohs et al. [1987], who estimated a 46\% cumulative incidence of AD by the age of 86 in the first-degree relatives of probands. Our prevalence rate of $30 \%$ reflects the lower mean age of 75 . Our rate is close to the $29 \%$ prevalence rate found in another study of all first-degree relatives (mean age, $67.5 \mathrm{yr}$ ) of 118 probands with AD [Silverman et al., 1994]. When we include relatives with very mild AD, the rate rises to $40 \%$.

Patients who were seen at our clinic with complaints of memory problems had a $91 \%$ sensitivity and $80 \%$ specificity to our question on the family history questionnaire. This may reflect their greater awareness of family history of AD, or, alternatively, it might be due to their assuming that memory impairment was pathological. Thus patients who see primary care physicians with complaints of memory problems would be expected to have a higher sensitivity for a family history than our overall sensitivity of $64 \%$, which included community patients who had not complained of memory problems where the sensitivity was $43 \%$.

A simple family history questionnaire appears to be a good predictor of the presence or absence of $\mathrm{AD}$ or like dementia among siblings of patients with late onset $\mathrm{AD}$. As with family history in other neuropsychiatric illnesses, the sensitivity of the questionnaire varies in AD. Clearly, education and the population base (clinic vs. community sample) as well as informant characteristics influence yield. Other factors that improve sensitivity include the use of a spouse or sibling of the proband as informant and face-to-face interviews. Furthermore, especially in the community, underreporting of dementia in male siblings seems to be an issue. Awareness of fac- 
tors that improve sensitivity will assist in the identification of AD among siblings in any group of patients.

\section{ACKNOWLEDGMENTS}

This work was supported by Federal Grants AG07232, AG10963, AG08702 and RR00645 and from the Charles S. Robertson Memorial Gift for Alzheimer's Disease Research from the Banbury Fund. We are also grateful for the assistance of Adria Gonzalez in compiling the data.

\section{REFERENCES}

Andreasen NC, Endicott J, Spitzer RL, Winokur G (1977): The family history method using diagnostic criteria. Arch Gen Psychiatry 34:1229-1235.

Andreasen NC, Rice J, Endicott J, Reich T, Coryell W (1986): The family history approach to diagnosis. Arch Gen Psychiatry 43:421-429.

Gurland B, Wilder D, Cross P, et al. (1995): Relative rates of dementia by multiple case definition, over two previous periods, in three cultural groups. Am J Ger Psychiatry 3:6-20.

Heun R, Maier W (1995): Risk of Alzheimer's disease in first degree relatives (Letter). Arch Gen Psychiatry 52:317-319.

Kawas C, Segal J, Stewart WF, et al. (1994): A validation study of the dementia questionnaire. Arch Neurol 51:901-906.

Kukull WA, Larson EB (1989): Distinguishing Alzheimer's disease from other dementias: Questionnaire responses of close relatives and autopsy results. J Am Geriatr Soc 37:521-527.

Li G, Aryan M, Silverman J, et al. (1997): The validity of the family history method for identifying Alzheimer's disease. Arch Neurol 54:634-640.

McKhann G, Drachman D, Folstein M, Katzman R, Price D, Stadlan FM (1984): Clinical diagnosis of Alzheimer's diseases: Report of the NINCDS-ADRDA Work Group under the auspices of Department of Health and Human Services Task Force on Alzheimer's disease. Neurology 34:939-944.

Mendlewicz J, Fleiss JL, Cataldo M, Rainer JD (1975): Accuracy of the family history method in affective illness: Comparison with direct interviews in family studies. Arch Gen Psychiatry 32:309-314.

Mohs RC, Breitner JCS, Silverman JM, Davis KL (1987): Alzheimer's disease: Morbid risk among first-degree relatives approximates $50 \%$ by 90 years of age. Arch Gen Psychiatry 44:405-408.

Morris JC, McKeel DWW, Storandt M, et al. (1991): Very Mild Alzheimer's disease: Informant-based clinical, psychometric, and pathologic distinction from normal aging. Neurology 41:469-478.

Ottman R, Hauser WA, Susser M (1993): Validity of family history data on seizure disorders. Epilepsia 34:469-475.

Ottman R, Hong S, Lipton RB (1993): Validity of family history data on severe headache and migraine. Neurology 43:1954-1960.

Silverman JM, Keefe RSE, Mohs RC, Davis KL (1989): A study of the reliability of the family history in genetic studies of Alzheimer's disease. Alzheimer's Dis Assoc Disord 3:218-222.

Silverman JM, Breitner JCS, Mohs RC, Davis KL (1986): Reliability of family history method in genetic studies of Alzheimer's disease and related dementias. Am J Psychiatry 143:1279-1282.

Silverman JM, Raiford K, Edland S, et al. (1994): The consortium to establish a registry for Alzheimer's disease (CERAD). Part VI. Family history assessment: A multicenter study of first-degree relatives of Alzheimer's disease probands and nondemented spouse controls. Neurology 44:12531259. 